\title{
In Vitro Starch Hydrolysis and Estimated Glycaemic Index of Biscuits from Unripe Banana Peel Flour
}

\author{
Syarifah Khadijah Syed Abu BAKAR, Noorlaila AHMAD and Fadhilah JAILANI* \\ Faculty of Applied Sciences, Universiti Teknologi Mara, 40450 Shah Alam, Malaysia
}

(Received June 7, 2019)

\begin{abstract}
Summary Banana peels are industrial waste that is normally being utilized for biogas production or disposed of without use. By converting banana peels into flour, the waste product can be reduced and the benefits that originate from its fibre and bioactive substances can enhance the nutritional value in other food products. Furthermore, the flour will increase the economical source of the industry as it is obtainable at a low-cost. The transformation of banana peels (waste) into flour (food ingredient) can improve the sustainability of the food chain and promote consumers' health. The unripe banana peel flour (UBPF) constitute of $41.4 \%$ total starch and $37.6 \%$ total dietary fibre with a higher percentage of insoluble dietary fibre than soluble dietary fibre. Various levels of UBPF from Berangan variety ranging from $0 \%$ to $40 \%$ were incorporated in the formulation of biscuits. The partial substitution of UBPF significantly increased the total dietary fibre content of biscuits from $1.83 \%$ to $4.70 \%$. Starch hydrolysis and estimated glycemic index (eGI) of biscuits were analysed by enzymatic in-vitro digestion. The result showed that partial substitution of Berangan BPF significantly decreased $(p<0.05)$ the starch digestion rate thus lowering the eGI of biscuits from high eGI food to intermediate GI food. UBPF has great potential as a functional ingredient to improve the nutritive value of foods as well as to reduce the glycemic index of food products.
\end{abstract}

Key Words banana peel flour, biscuits, glycaemic index, total starch, dietary fibre

High carbohydrate foods have varied effects on postprandial glycemic response. Therefore, the foods are categorised based on their postprandial glycemic response with the help of GI value. GI value is a parameter that indicates the blood glucose response after food is consumed by human (1). According to (2), low GI foods are digested and absorbed slowly which may decrease the rise of glucose and insulin levels. Meanwhile, the consumption of high GI products gets digested and absorbed rapidly. This is followed by increasing glucose released and insulin secretion.

Banana peels are beneficial to health as it contains good therapeutic and nutritional values. Banana peels are a good source of dietary fibre and antioxidants. Dietary fibre has the potential to treat constipation and improve the general health and well-being of human (3). Banana peels are a good source of soluble dietary fibres, such as pectins and fructans among many others. These will help reduce the risk of colon cancer and lower serum cholesterol (4). As for antioxidants, they are known to have beneficial health-promoting properties such as strengthening the body immunity system, reducing the risk of metabolic diseases and delaying the ageing process (5).

Biscuit is a popular baked product consumed by people around the world due to its long shelf life, delicious taste and affordability. Biscuits are available in many

\footnotetext{
*To whom correspondence should be addressed.

E-mail: fj.fst.uitm@gmail.com
}

different flavours and they are always ready for consumption. Commercial biscuits made from wheat flour usually contain a higher amount of sugar, fat, easily digested starch and low level of dietary fibre $(6,7)$. Therefore, substituting wheat flour with fruits or vegetables waste flour as the new ingredient can improve the quality and nutritional values of biscuits. There is a limited study in the utilization of unripe Berangan banana peel flour on GI value in biscuits and most of the studies used a well-known cultivar such as Cavendish type. In this study, the in vitro rate release of starch, hydrolysis index (HI) and GI values of biscuit made from $0 \%, 10 \%, 20 \%, 30 \%$ and $40 \%$ of UBPF were analysed. The GI value of biscuit is expected to decrease due to UBPF substitution as (8) mentioned that the predicted GI value can be altered with the combination of other ingredients in food formulation.

\section{MATERIALS AND METHODS}

Preparation of unripe banana peelflour (UBPF). Unripe Berangan was purchased from Klang, Selangor and black-spot freed. The peel was washed, separated from the pulp and treated with $0.2 \%$ citric acid and $0.2 \%$ sodium metabisulfite. Then, the peel was dried at $60^{\circ} \mathrm{C}$ for $\pm 12 \mathrm{~h}$, ground and sieved pass through a 40-mesh screen ASTM. The flour was kept into an air-tight container.

Biscuit preparation. The ingredients used for the preparation of biscuits consist of butter, wheat flour, banana peel flour, castor sugar, cornflour, cocoa and 
salt. Butter was mixed until light and fluffy. Then, sugar was added and mixed for about 2 min. Dry ingredients were added slowly and formed a dough. The dough was rolled into $10 \mathrm{~mm}$, molded and baked for 10-12 min at $160^{\circ} \mathrm{C}$.

Chemical analysis. Total starch content of UBPF was determined according to (9) while total dietary fibre (TDF) determination was carried out using the enzymatic-gravimetric method 991.43 (10). Moisture, ash, crude fat, crude protein content of the biscuits were determined using the method described by (11). The carbohydrate content was calculated by the difference. The results were expressed in percentage.

In vitro starch hydrolysis and estimated glycemic index. In-vitro starch digestion rate and estimated glycemic index were determined according to (9). About $10 \mathrm{~mL}$ of $\mathrm{HCl}-\mathrm{KCl}$ buffer with $\mathrm{pH} 1.5$ was added into $50 \mathrm{mg}$ of defatted sample. Next, about $0.2 \mathrm{~mL}$ of solution containing $1 \mathrm{~g}$ of pepsin in $10 \mathrm{~mL}$ of $\mathrm{HCl}-\mathrm{KCl}$ was added into each sample and incubated for $1 \mathrm{~h}$ at $40^{\circ} \mathrm{C}$ in a shaking water bath. Then, the volume of the mixture was increased by adding with Tris-Meleate buffer with pH 6.9 until $25 \mathrm{~mL}$. Upon doing so, $5 \mathrm{~mL}$ of $\alpha$-amylase in Tris-Meleate buffer containing 2.6 UI was added in each sample and incubated in shaking water bath at $37^{\circ} \mathrm{C}$. $3 \mathrm{~mL}$ of aliquot from each tube was taken out and placed in a tube at $100^{\circ} \mathrm{C}$ and shaken for $5 \mathrm{~min}$ at every $30 \mathrm{~min}$ interval within $3-\mathrm{h}$. This is to deactivate the enzyme. After shaking, the aliquot was refrigerated until the end of incubation time.

The next step was to hydrolyse the digested starch into glucose by adding $3 \mathrm{~mL}$ of $0.4 \mathrm{M}$ sodium acetate buffer with $\mathrm{pH} 4.75$ to each aliquot. The sample was incubated for $45 \mathrm{~min}$ at $60^{\circ} \mathrm{C}$ in a shaking water bath and then $60 \mu \mathrm{L}$ of amyloglycosidase was added into each tube. The volume of aliquot was adjusted to 10-100 mL with distilled water. Lastly, $0.5 \mathrm{~mL}$ aliquot of triplicate was taken out and incubated with glucose assay kit (glucose oxidase). The colour of aliquot was measured at $540 \mathrm{~nm}$ using an ultraviolet-visible (UVVis) spectrophotometer (Perkin Elmer, Lambda 35, California, USA). The rate of starch digestion was expressed as percentage of total starch hydrolysed at different times $-30,60,90,120$ and $180 \mathrm{~min}$.

Statistical analysis. The obtained data were analysed using a one-way Analysis of Variance (ANOVA) exploiting Statistical Package for Social Science (SPSS) to test the level of significance $(p<0.05)$.

\section{RESULTS AND DISCUSSION}

The chemical compositions of UBPF were presented in Table 1. According to (12), Berangan banana peel flour exhibited highest total starch content compared to other varieties; Nangka, Tanduk and Rastali banana peel flour. The amount of total dietary fibre content in banana peels found in this study is slightly higher than those reported by (13). TDF mainly comprise of soluble (beta glucan, inulin, fructooligosaccharides, pectin, gums) and insoluble (cellulose, lignins, some hemicellulose) fibre fractions. The insoluble fractions dominate
Table 1. Total starch and total dietary fibre content of unripe banana peel flour.

\begin{tabular}{lr}
\hline \multicolumn{1}{c}{ Compositions } & \multicolumn{1}{c}{ UBPF } \\
\hline Total starch $(\mathrm{g} / 100 \mathrm{~g})$ & $41.4 \pm 0.17$ \\
Total dietary fibre $(\mathrm{g} / 100 \mathrm{~g})$ & $37.63 \pm 0.15$ \\
\hline
\end{tabular}

Mean values \pm standard deviation of triplicate determinations, $\mathrm{UBPF}=$ unripe banana peel flour.

the percentage of fibre content in most varieties of banana including Berangan (12). According to Ref. (14), the factors that contribute to the different total starch content and total dietary fibre of plant includes the variety of fruits, stage of maturity, cultivation as well as ripening condition.

Chemical compositions of biscuits incorporated with different amount of UBPF are shown in Table 2. It is apparent from the table that the moisture content of all biscuits in this study was below than $10 \%$, which is the expected value for baked products as low moisture can prevent spoilage and extend shelf life (15). Ash content indicates the presence of minerals in the biscuits. Ash content in biscuits showed no significant difference as the level of UBPF in formulations increased $(p<0.05)$. The previous study shows that the ash content of biscuits made from mango peel, guava peel and papaya peel was $0.93 \%$ to $1.00 \%, 3.30 \%$ to $4.20 \%$ and $3.80 \%$ to $4.50 \%$, respectively $(16-18)$. This variation is due to the different concentration of minerals on each type of food waste.

The fat content of biscuits increased from $24.2 \%$ to $30.7 \%$ as the level substitution of Berangan BPF increased. The increased fat content is probably contributed by the fat present in UBPF (12) which was higher than wheat flour $(1 \%)$. Banana peels have greater fat content $(3.95 \%)$ compared to sweet orange peels and lemon peels (2.6 g/100 $\mathrm{g}$ and $2.5 \mathrm{~g} / 100 \mathrm{~g})(19)$.

The protein content of biscuits ranged between $3.30 \%$ and $3.77 \%$. A similar observation had been reported by (20) in which biscuit incorporated plantain peel flour $(0 \%, 5 \%, 10 \%$ and $15 \%)$ showed a significant decrease in protein content $(8.99 \%$ to $11.32 \%$, respectively). The decrease of protein content may be due to the reduced quantity of wheat flour used in making biscuit as the ingredient has high gluten protein content.

As shown in Table 2, the total carbohydrate content of biscuits incorporated with UBPF was significantly reduced as the percentage of UBPF increased $(p<0.05)$. This observation shows that the carbohydrate content was significantly affected when UBPF was introduced into the biscuit formulations. This result can be explained with the fact that wheat flour is a superior source of carbohydrate. Substituting wheat flour with Berangan BPF had reduced the amount of wheat flour used in the formulation thus decreasing the carbohydrate content in the biscuits (21).

On average, biscuits added with the highest substitution of UBPF contain the highest amount of TDF $(p<$ 
Table 2. Chemical compositions of biscuit substituted with unripe banana peel flour.

\begin{tabular}{|c|c|c|c|c|c|}
\hline Formula & $0 \%$ & $10 \%$ & $20 \%$ & $30 \%$ & $40 \%$ \\
\hline Moisture (\%) & $2.13 \pm 0.30^{\mathrm{a}}$ & $2.39 \pm 0.53^{\mathrm{a}}$ & $2.45 \pm 0.48^{\mathrm{a}}$ & $2.52 \pm 0.31^{\mathrm{a}}$ & $2.66 \pm 0.65^{\mathrm{a}}$ \\
\hline Ash $(\%)$ & $1.66 \pm 0.42^{\mathrm{a}}$ & $1.66 \pm 0.30^{\mathrm{a}}$ & $1.73 \pm 0.58^{\mathrm{a}}$ & $1.86 \pm 0.12^{\mathrm{a}}$ & $2.11 \pm 0.50^{\mathrm{a}}$ \\
\hline Crude fat (\%) & $24.2 \pm 0.17^{\mathrm{e}}$ & $26.7 \pm 0.26^{\mathrm{d}}$ & $27.1 \pm 0.10^{\mathrm{c}}$ & $27.8 \pm 0.26^{\mathrm{b}}$ & $30.7 \pm 0.20^{\mathrm{a}}$ \\
\hline Crude protein (\%) & $3.77 \pm 0.06^{\mathrm{a}}$ & $3.77 \pm 0.15^{\mathrm{a}}$ & $3.70 \pm 0.10^{\mathrm{a}}$ & $3.60 \pm 0.20^{\mathrm{a}}$ & $3.30 \pm 0.20^{b}$ \\
\hline Total carbohydrate (\%) & $68.25 \pm 0.30^{\mathrm{a}}$ & $65.48 \pm 0.63^{b}$ & $65.69 \pm 0.15^{\mathrm{b}}$ & $64.23 \pm 0.36^{c}$ & $61.23 \pm 0.22^{\mathrm{d}}$ \\
\hline Total dietary fibre (\%) & $1.83 \pm 0.56^{\mathrm{e}}$ & $2.43 \pm 0.15^{\mathrm{d}}$ & $3.07 \pm 0.15^{\mathrm{c}}$ & $3.33 \pm 0.15^{\mathrm{b}}$ & $4.70 \pm 0.20^{\mathrm{a}}$ \\
\hline
\end{tabular}

Mean values \pm standard deviation of triplicate determinations. Different superscript letters in each row indicate significant differences $(p<0.05)$.

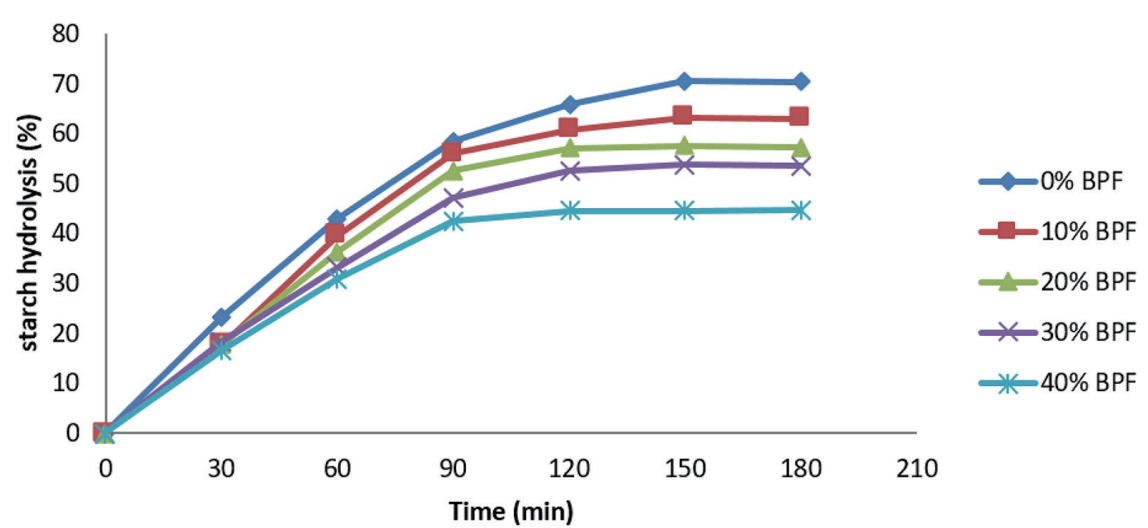

Fig. 1. Starch hydrolysis rate of biscuits substituted with unripe banana peel flour.

0.05). TDF content in biscuits increased by 2-fold as compared to biscuits without the substitution of UBPF. The findings observed in this study mirror those of the previous studies that have examined the effect of fruit wastes obtained from mango peel, raspberry pomace, plantain peel and pineapple pomace on dietary fibre content in biscuits and cookies $(20,22-24)$. Different fruit wastes with $5 \%, 10 \%, 15 \%, 20 \%$ and $25 \%$ percentages were substituted with wheat flour and it was determined that all cookies had higher dietary fibre content than control. According to (25), food with a dietary fibre content of $3 \mathrm{~g} / 100 \mathrm{~g}$ can be labelled as a source of dietary fibre. Therefore, biscuits incorporated with 20\%, $30 \%$ and $40 \%$ of Berangan BPF can be considered likewise because the amount of dietary fibre has met the requirement.

An in vitro enzymatic digestion was conducted to simulate the action of biscuits when eaten. The glucose released from the breakdown of starch in biscuits during enzymatic digestion was measured and observed for $180 \mathrm{~min}$. Figure 1 shows the impact of the substitution of different level of UBPF in biscuits. During the first $30 \mathrm{~min}$ of reaction, the hydrolysis rate increased rapidly for all samples. Hydrolysis rate of $10 \%, 20 \%$, $30 \%$ and $40 \%$ UBPF biscuits were ranged between $17.65 \%$ to $16.70 \%$. As expected, starch in $0 \%$ UBPF (23.22\%) biscuit hydrolysed faster compared to substituted biscuits in the first $30 \mathrm{~min}$. Thereafter, the hydrolysis rate of all samples kept increasing to its peak at $90 \mathrm{~min}$ before slowing down towards $120 \mathrm{~min}$. The re- action shows plateau state after 120 min until the end of observation time. Hydrolysis rate of control, $10 \%$, $20 \%, 30 \%$ and $40 \% \mathrm{UBPF}$ at $180 \mathrm{~min}$ were $70.37 \%$, $62.98 \%, 57.22 \%, 53.56 \%$ and $44.68 \%$, respectively.

Control biscuit ( $0 \% \mathrm{UBPF})$ exhibited faster release of glucose and higher digestion rate than UBPF biscuits. As the level of UBPF substitution in biscuits increased, the starch hydrolysis rate decreased. About 57.50\% reduction was observed in starch hydrolysis rate when $40 \%$ of UBPF was substituted with wheat flour in the biscuit formulations. According to (7), proteins and fibre are the reason for the slower and lower increase of the glucose in in vitro method as both macronutrients acted as a barrier towards starch digestibility. The interaction between dietary fibre and non-fibrous components developed a close and compact structure of baked product with protein and starch molecules entrapment. Thus, the entrapped starch reduces the susceptibility of enzyme attack and therefore reduces the release of glucose (8).

These results reflect those of (26), who also found that the low starch digestibility in fibre enriched biscuit obtained as dietary fibre content increased. This is due to water holding capacity of dietary fibre that produces less water for starch gelatinisation and starch swelling resulting in low digestibility rate.

HI value was calculated from the starch hydrolysis curves whereas eGI values of biscuit were calculated based on the correlation equation between HI and eGI obtained from the digestion of starch of each biscuit. 
Table 3. Hydrolysis index (HI) and estimated glycemic index (eGI) of biscuits substituted with unripe banana peel flour.

\begin{tabular}{rcc}
\hline Formula & HI $(\%)$ & eGI \\
\hline $0 \%$ & $55.27 \pm 0.50^{\mathrm{a}}$ & $70.07 \pm 0.31^{\mathrm{a}}$ \\
$10 \%$ & $50.03 \pm 0.06^{\mathrm{a}}$ & $67.17 \pm 0.06^{\mathrm{b}}$ \\
$20 \%$ & $46.43 \pm 0.07^{\mathrm{b}}$ & $65.20 \pm 0.01^{\mathrm{c}}$ \\
$30 \%$ & $43.13 \pm 0.64^{\mathrm{c}}$ & $63.40 \pm 0.35^{\mathrm{d}}$ \\
$40 \%$ & $37.27 \pm 0.76^{\mathrm{d}}$ & $60.19 \pm 0.38^{\mathrm{e}}$ \\
\hline
\end{tabular}

Values represent the mean \pm standard deviation. Different superscript letters in each column indicate significant differences $(p<0.05)$.

Table 3 showed the HI and eGI values of the biscuits. Formulation of $0 \%$ and $10 \%$ UBPF biscuits showed significantly greater values of $\mathrm{HI}$ compared to $20 \%, 30 \%$ and $40 \%$ UBPF biscuit $(p<0.05)$. HI value of biscuits decreased from $55.27 \%$ to $37.27 \%$ and the lowest $\mathrm{HI}$ value of $37.27 \%$ was observed in $40 \%$. From the observation, the substitution of UBPF with wheat flour biscuit preparation slows down the rate of starch hydrolysis thus it can be correlated with the decrease of HI. According to Ref. (3), meals containing protein and dietary fibre might affect the breakdown process of food and reduce the digestion by $\alpha$-amylase in saliva which led to a reduced HI value. Therefore, the reduction of HI value is a result of less digestion starch.

The eGI value significantly decreased as the level of UBPF used in biscuits preparation increased $(p<0.05)$. The eGI value of $0 \%$ (70.07) observed to be higher compared to others. According to (1), foods with GI value of $\leq 55,56-69$ and $\geq 70$ were classified as low, medium and high GI food, respectively. From the result presented in Table 3, it can be observed that the eGI value of $0 \%$ UBPF falls within the category of high glycemic index food while all UBPF substituted biscuits fall within intermediate glycemic index food. The reduction in eGI value could be attributed by the fraction of dietary fibre content among biscuits. Similar to the observation made by (15), the addition of purple rice flour in biscuits significantly increased TDF content and reduced the eGI value of the food.

According to (27), dietary fibre is capable to delay glycemic response of food by slowing the nutrient absorption and extend the transit time in the small intestine. Ref. (2) explained that interaction between starch, protein network and fibre might affect the starch digestion. The interaction might form a matrix with protein, developing a barrier around the starch granules and reducing the digestive enzyme activity hence resulting in low $\mathrm{HI}$ and GI.

\section{CONCLUSION}

In vitro digestion analysis conducted in the study has highlighted that the substitution of UBPF in biscuits decreases the digestion rate and slows the increase of glucose released, and reduces the HI values of biscuits.
Biscuit samples containing 10\%, 20\%, 30\% and 40\% UBPF showed significant lower GI values compared to the control biscuit sample. The GI value of biscuits substituted with UBPF falls in the category of intermediate glycemic index foods. Also, the low digestibility of starch values shows that the UBPF incorporated biscuits may be useful as functional foods for people requiring healthy biscuits.

\section{Disclosure of state of COI}

No conflicts of interest to be declared.

\section{Acknowledgments}

The authors would like to acknowledge the Ministry of Higher Education (MoHE) and Universiti Teknologi MARA (UiTM) Shah Alam for granting the following projects (600-RMI/FRGS 5/3 (27/2015) \& 600-IRMI 5/3/GIP $(011 / 2018))$.

\section{REFERENCES}

1) Odenigbo AM, Asumugha V, Ubbor S, Ngadi M. 2013. In vitro starch digestibility of plantain and cookingbanana at ripe and unripe stages. Int Food Res J 20: 3027-3031.

2) Foschia M, Peressini D, Sensidoni A, Anne M, Stephen C. 2015. Synergistic effect of different dietary fibres in pasta on in vitro starch digestion. Food Chem 172: 245 250.

3) Chakraborty C, Mukherjee A, Bornini B, Shubham M, Bandyopadhyay K. 2017. Utilization of banana peel and pulp as a functional ingredient in product development: A review. Int J of Eng Res and Sci \& Tech 3: 137-148.

4) Happi ET, Robert C, Ronkart SN, Wathelet B, Paquot M. 2008. Dietary fibre components and pectin chemical features of peels during ripening in banana and plantain varieties Bioresour Technol 99: 4346-4354.

5) Nur S, Abdul A, Haron H, Aida W, Mustapha W, Shahar S. 2017. Physicochemical properties, total phenolic and antioxidant activity of mixed tropical fruit juice, TP 3 in 1 TM. J of Agri Sci 9: 50-61.

6) Hettiaratchi UPK, Ekanayake S, Welihinda J. 2012. Prediction of glycaemic indices (GI) of meals by starch hydrolysis indices. Int Food Res J 3: 1153-1159.

7) Klunklin W. 2018. Physicochemical properties and sensory evaluation of wheat-purple rice biscuits enriched with green-lipped mussel powder (Perna canaliculus) and Spices. J of Food Qual, p 1-9.

8) Ho L, Tan T, Aziahabdul N, Bhat R. 2015. Food bioscience in vitro starch digestibility of bread with banana (Musa acuminata $\times$ balbisiana ABB cv. Awak) pseudostem flour and hydrocolloids. Food Biosci 12: 10-17.

9) AOAC. 2000. Official methods of analysis of International (17th ed.). Gaitherburg. USA: AOAC International Inc.

10) Goñi I. 1997. A starch hydrolysis procedure to estimate glycemic index. Nutr Res 3: 427-437.

11) AOAC. 1995. Official Methods of Analysis (15th ed). Arlington, VA, USA.

12) Bakar SKSA, Ahmad N, Jailani F. 2018. Chemical and functional properties of local banana peel flour. J of Food and Nutr Res 8: 492-496.

13) Singanusong R, Tochampa W, Kongbangkerd T, Sodchit C. 2014. Extraction and properties of cellulose from banana peels. J Sci Technol 3: 201-213. 
14) Happi T, Herinavalona R, Wathelet B, Tchango J, Paquot M. 2007. Food chemistry effects of the stage of maturation and varieties on the chemical composition of banana and plantain peels. Food Chem 103: 590-600.

15) Klunklin W, Savage G. 2018. Effect of substituting purple rice flour for wheat flour on physicochemical characteristics, in vitro digestibility, and sensory evaluation of biscuits. J of Food Qual, p 1-8.

16) Aslam HKW, Ianam M, Raheem U, Ramzan R, Shakeel A, Shoaib M, Sakandar HA. 2014. Utilization of mango waste material (peel, kernel) to enhance dietary fiber content and antioxidant properties of biscuit. J Glob Innov Agric Soc Sci 2: 76-81.

17) Maria S, Bertagnolli M, Liliane M, Silveira R, Fogaça ADO, Umann L, Penna NG. 2014. Bioactive compounds and acceptance of cookies made with guava peel flour. Food Science and Technology 34: 303-308.

18) Bokaria K. 2016. Development of papaya peel flour based cookies and evaluation of its quality. J of Multidisciplinary Eng Sci and Technoly 12: 6393-6396.

19) Keran H, Salkić M, Odobašić A, Jašić M, Ahmetović N, Šestan I. 2009. The importance of determination of some physical chemical properties of wheat and flour. Agric Conspec Sci 74: 197-200.

20) Arun KB, Persia F, Aswathy PS. 2015. Plantain peel-a potential source of antioxidant dietary fibre for developing functional cookies. J Food Sci Technol 10: 63556364.
21) Fatmawati A, Gunawan KY, Baharudin F, Tadza MYM, Mohd SN, Agustin YE, Padmawijaya KS. 2017. Physical characteristics, chemical composition, organoleptic test and the number of microbes in the biscuits with addition of flour banana peels. J of Phys 812: 1-6.

22) Ajila CM, Leelavathi K, Rao UJSP. 2008. Improvement of dietary fiber content and antioxidant properties in soft dough biscuits with the incorporation of mango peel powder. J of Cer Sci 48: 319-326.

23) Devi LK, Karoulia S, Chaudhary N. 2016. Preparation of high dietary fibre cookies from pineapple (Ananas comosus) pomace. Int J of Sci and Res 5: 1368-1372.

24) Górecka D, Pacho B, Dziedzic K. 2010. Raspberry pomace as a potential fiber source for cookies enrichment. Acta Scientiarum Polonorum, Technologia Alimentaria 9: 451-462.

25) Sulong F. 2012. Updates on nutrition labelling and claims regulations food regulations. 1985. Thailand.

26) Han S, Daniel S, Amir W, Wan N, Rosli W, Ishak W. 2017. Incorporation of dietary fibre-rich oyster mushroom (Pleurotus sajor-caju) powder improves postprandial glycaemic response by interfering with starch granule structure and starch digestibility of biscuit. Food Chem 227: 358-368.

27) Trinidad TP, Mallillin AC, Sagum RS, Encabo RR. 2010. Glycemic index of commonly consumed carbohydrate foods in the Philippines. J of Funct Foods 4: 271-274. 